\title{
Institute for \\ Research on \\ Poverty
}

\section{Discussion Papers}

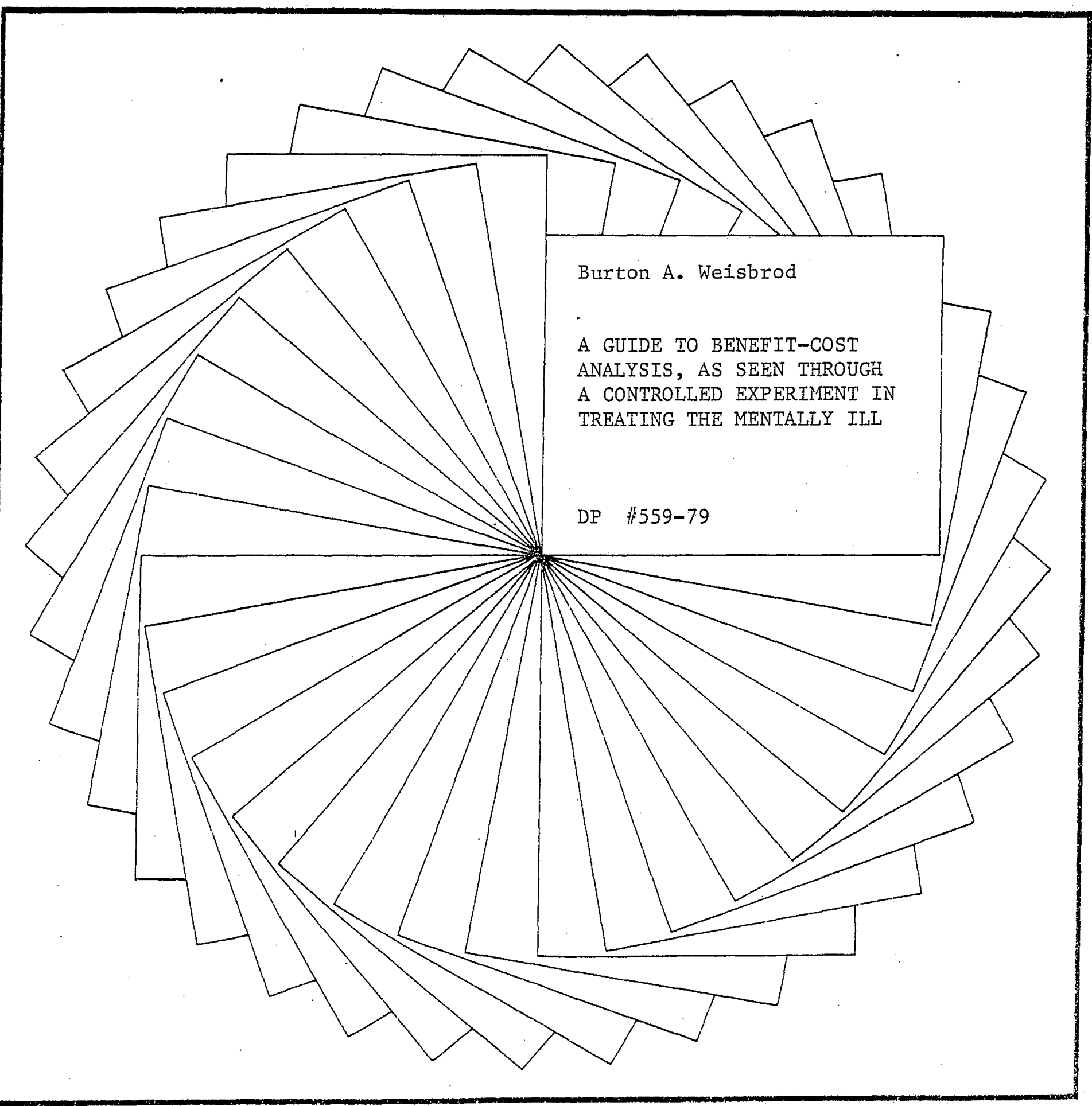


A Guide to Benefit-Cost Analysis, as Seen Through

A Controlled Experiment in Treating the Mentally III

\author{
Burton A. Weisbrod \\ Professor of Economics \\ University of Wisconsin-Madison
}

August 1979

This research would not have been undertaken but for the interest of Dr. Leonard Stein, who proposed undertaking an economic benefit-cost analysis in conjunction with the experiment that he and Dr. Mary Ann Test were designing at the Mendota Mental Health Institute, where they were, respectively, Director and Associate Director of Research. Their help throughout the economic study was valuable. I thank ther'. I also thank Margaret Helming, A. James Lee and Olivia Mitchell, who served as research analysts at various stages in the economic analysis; they me to significant contributions. Susan Feigenbaum, Steven LaValley, and Steven Verrill also provided important research assistance. Helpful comments on an earlier draft of this paper were made by Janice Giesige. This study was supported by Grant 05-R-000009 from the National Institute of Mental Health, by the Health Economics Research Center, and by funds granted to the Institute for Research on Poverty at the University of Wisconsin-Madison by the Department of Health, Education, and Welfare pursuant to the provisions of the Economic Opportunity Act of 1964. 


\section{ABSTRACT}

The study reported on here is the first benefit-cost analysis of a controlled (random assignment): experient in the mental health field. It compares, in terms of an unusually wide variety of "tangible" and "intangible" forms of benefits and costs, a traditional, hospital-based approach to treating the mentally ill with a nontraditional communteybased approach.

From one point of view this study is simply one more benefit-cost analysis of a social welfare program. As such its interest is to those academicians and policy planners who are concerned with public policy toward the mentally ill. From another point of view, however, this is also a report on the use of a randomized experimental design for identifying differential effects of policy alternatives.

From yet a third perspective, this study illustrates both the importance and the feasibility of collaboration between economists and experts in the substantive area involved--mental health professionals in this case--in the design and execution of evaluative research. And from a fourth perspective it is a guide to the avoidance--or, at least, the reduction--of errors in applied benefit-cost analysis and of misunderstandings between analysts and users.

Awareness of mental illness and its treatability seems to be growing, and so the real resource implications of the choice of treatment mode are of increasing importance. In the context of debate over national health insurance there has been scant attention to mental illness, and even less to the choice among alternative types of delivery systems. The research reported here supports the hypothesis that hospitalization of the mentally ill is, except for emergency situations, less effective than community-based treatment of approximately equal cost. The research also confirmed the hypothesis that the forms taken by the social costs of alternative programs can be so different that it is easy to mistake a change in the form of costs for a change in their level. Finally, this study highlights the fact that benefit-cost analysis, despite advances at both the conceptual and empirical levels, remains a mixture of science and art. 
A Guide to Benefit-Cost Analysis, as Seen Through

A Controlled Experiment in Treating the Mentally I11

\section{INTRODUCTION}

This paper has three goals: (I) to present a new benefit-cost $(B-C)$ analysis of two alternative approaches for treating the mentally ill; (2) to guide the prospective benefit-cost analyst working in any area, but especially in human services, in achieving a comprehensive view of the range of costs and benefits; and (3) to emphasize the importance and feasibility of including all relevant variables in any $B-C$. analysis even if their monetary valuation is impractical.

With mental illness and its treatment becoming increasingly common and costly, and with the already large public sector role continuing to grow, the $B-C$ analysis presented here is important in its own right as a guide to resource allocation. We use this analysis, however, to go beyond the mental illness area, to generalize about certain common issues in $\mathrm{B}-\mathrm{C}$ anaysis, for example, the usefulness of financial accounting data in cost estimation work, the relevance of distributional effects, and the handling of "incommensurables" (costs and benefits that have not been translated into pecuniary terms).

Economic research on the evaluation of governmental programs has extended to a wide variety of activities, ${ }^{1}$ and in recent years it has increasingly utilized the methodology of controlled experimentation. ${ }^{2}$ The study reported on here is the first $B-C$ analysis of a controlled (random assignment) experiment in the mental health field. It compares, in terms of an unusually wide variety of tangible and intangible forms 
of benefits and costs, a traditional hospital-based approach to treating the mentally ill with a non-traditional community-based approach, each to be described below.

From one point of view, this study is simply one more $B-C$ analysis of a social welfare program. As such, its interest is to those academicians and policy planners who are concerned with public policy toward the mentally ill. From another point of view, however, this is also a report on the use of a randomized experimental design for identifying differential effects of policy alternatives. It is, then, a contribution to the growing literature assessing the strength and limitations of this approach in the real, as distinguished from the textbook, world.

From yet a third perspective, this study illustrates both the importance and the feasibility of collaboration between economists and experts in the substantive area involved (here, mental health professionals) in the design and execution of evaluative research. And from a fourth perspective, it shows how to avold, or at least reduce both exrors in applied B-C analysis and misunderstandings between analysts and users. The use of B-C analysis in public decision making has been criticized for reducing policy decisions to relying only on comparisons of dollar quantities while omitting effects not easily expressed in monetary terms or for which the assignment of monetary values can be made only arbitrarily. ${ }^{3}$ If a B-C analysis is performed properly, however, it will take into account as many as possible of the relevant variables, whether or not they can be either assigned money values or even quantified in non-monetary terms. . If such varilables are made explicit, decision-makers will be less likely to overlook them. 
Another criticism of $B-C$ analysis is that it often seems to imply that decisionmakers can and should focus on economic efficiency, the assumption being that any adverse equity effects can and will be neutralized by other public action (compensation). The critical point, however, is that the incidence of spending decisions usually cannot be so easily offset, especially if the policies and projects under consideration would generate distributional effects outside the geographic and fiscal jurisdiction of the political dectsion-making unit. Thus, such units, faced with very real budget constraints, have a legitimate interest in learning what expenditures they would have to make, as well as what nonmonetary costs and benefits would accrue to them, if a given program were to be adopted. Hence, decisions and the analyses on which they are based, should take distributional effects into account, in addition to assessments of efficiency consequences.

\section{ANALYTIC FRAMEWORK}

The policy choice under study in this paper, between two alternative approaches for treating the mentally ill, poses the problems of what to measure and how to measure it in particularly stark terms. The very definition of "mental illness" is controversial, as are measures of the costs and benefits of its cure. Monetary values based on productivity gains and losses or on observed willingness to pay by patients and their families are, moreover, clearly incomplete because of patients' inability to make informed choices, and because of "external" effects. The possibility that external effects are sizable implies that assessment of costs and benefits must consider not merely the direct beneficiaries (patients in this 
case) but also a wide variety of other persons. Dispersion of costs and benefits beyond the group that constitutes the target is likely to be great in the mental health area, where treatment cost burdens fall not only upon individual patients, but also upon their families, as well as. private philanthropists, insurers, and 1ocal, state, and federal government taxpayers. Similarly, psychic costs of mental iliness are borne not only by the ill person but also by family members and others with whom the 111 person comes in contact.

Any B-C analysis, therefore, in any project area, should carefully consider a11 consequences extending beyond the target group. Otherwise, the result can be that a shift in the form of a cost or benefit will be misinterpreted or misestimated as a change in the magnitude of total costs or benefits. 5

In the given context of treating the mentally or physically ill, for example, a program that saves hospital resources by discharging patients from hospitals more quickly than usual will indeed reduce costs of hospitalization but will also shift costs to family members who care for the patient at home. Moreover, whereas hospitalized patients do not often become police problems, an early discharge program may well impose costs on the police system. If the released patients have contacts with law enforcement agencies. In evaluating a proposed deinstitutionalization program, therefore, the $B-C$ analyst should not overlook the possibility that savings in real hospital costs could be offset by increases in law enforcement or other costs.

The point here is that any B-C analysis should begin by developing a comprehensive accounting framework which minimizes the probability that competing programs which involve benefits and costs merely in differing 
forms will mistakenly be found to be of differing overall magnitudes. In designing the benefit-cost analysis reported on here, we began with the development of just such a comprehensive framework. Even if it turned out that some forms of costs or benefits could not be measured, the accounting framework would, at least, make explicit the ommissions and thereby would indiacte the direction or probable estimation bias.

In general, the framework for any benefit-cost analysis (that is, for assessing the net present value of any project, $v_{j}$ ) may be summarized as follows:

$V_{j}=\sum_{t=1}^{T} \frac{B_{t}-C_{t}}{(1+r)^{t}}$

where: $B_{t}=$ Benefits from the proposed program in year $\underline{t}$. $c_{t}=$ Costs of the proposed program in year $t$. $T=$ the planning horizon, and $r=$ discount rate.

If $v_{j}>0$, the project is efficient. The key problems, of course, are what to include in the benefits and costs, and which discount rate and planning horizon to use. In the case of the mental health experiment, data were obtained for only 14 months; there is little need, therefore, to select a value for $r$, given that we can only observe results for a relatively short time interval. (Some comments will be made, however, about the consequences of the limited duration of the experiment.) Since the $B s$ and $C s$ in this benefit-cost analysis are viewed from a social perspective, our concern is with real benefits and costs, whether or not pecuniary exchanges are involved. (We shall see, however, 
that the distinction between real and pecuntary Itransfer $T$ changes can be difficult to make operational, even though the conceptual distinction is clear.)

As noted above, the external effects of treating the mentally ill are likely to be substantial. One consequence is that willingness to pay for treating the mentally 111 cannot be thought of in terms of a private good analog, in which the mentally 111 alone are seen as demanding treatment. Other affected persons also have demands for treating the mentally 111, as do persons who, while not affected in a conventional sense, have interdependent utility functions that include as arguments the mental health state of others. ${ }^{7}$ Even apart from externalities, patients' own willingness to pay is not a satisfactory decision-making criterion, given that the mentally ill are not always able to make rational evaluations. In the quantitative estimates presented below, we attempt to measure the consequences of two treatment modes and thereby the difference in aggregate social willingness to pay for the two types of programs. 8

Structuring the benefit-cost analysis is one step; employing the structure to measure the variables once identifled, is another. Some of the forms of benefits and costs that have initially been deemed to be relevant will be satisfactorily measured in pecuniary units, For other forms, pecuniary measures will be available but controversial. For example, the number of lives saved or lost by some program might be presented in pecuniary terms, utilizing one or another procuedure; ${ }^{9}$ alternatively, that number of lives might simply be presented, thereby leaving it to some decisionmaker to provide, explicitly or tmplicitly, the value 
weight that will permit comparison. For still other forms of benefits or costs, there may be no available measure in pecuniary terms that

is at all satisfactory.

This is not to say that any vartable is, in prinicple, immeasurable. For some variables, however, either the conceptual foundation for measurement may be too weak to justify our presenting a pecuniary measure, or the costs of implementing the measure may be too high. For the same reasons, some variables will not be measured even in quantitative non-pecuniary terms; a qualitative (algebraic s1gn) indicator will sometimes be the optimal measure, e.g., for the burdens on community members when the mentally 111 live in residential areas. Finally, for some variables, the best that can be done will be no explicit measurement at all; a blank space in a tabulation of benefits and costs is optimal. In short an optimal benefit-cost analysis--by contrast with an ideal one--will measure variables with varying degrees of perfection. Thus, the expectation for the mental health treatment programs (as for virtually any program or project in any field) was that implementation of the comprehensive benefit-cost framework would result in all of the following: some variables would be measured in pecuntary terms, some in quantitative but not pecuniary terms, some in qualitative terms, and some not at all. This discussion implies, therefore, that benefit-cost analysis cannot be the sole basis for intelligent decision making.

\section{TREATING THE MENTALLY ILL: EXPERIMENTAL DESIGN}

Recent advances in pharmacology have revolutionized treatment of the mentally ill. This, together with changed social attitudes toward 
"warehousing" the mentally ill (institutionalizing them without treatment), has brought about sharp reductions both in the number of persons entering mental hospitals and the mean length of their stay. As Table 1 shows; the number of patients in mental hospitals has plummeted by some 60 percent from 1ts peak of 559,000 in 1955 to 216,000 in 1974, and to an even lower level today. As the table also shows, however, the number of admissions has more than doubled during the period, from 153,000 to 375,000 . With the increased turnover rate has come a phenomenon termed the "revolving door" syndrome--repeated admissions and discharges--which had led many experienced mental health professionals to wonder whether hospitalization might not actually be counterproductive for most patients. 10 If it is, then one or both of the following empirical hypotheses would hold:

Hypothesis I: Patients treated in the hospital would have less favorable outcomes than would otherwise identical patients who were . treated outside in a less dependency-creating environment.

Hypothesis II: The long run cost of treating the menta1ly 111 outside the hospital would be lower than the cost of treating them in the type of hospital-based program currently in widespread use.

In the experiment to which we turn now, a comparison is made between the hospital-based treatment program in general use today, called here the Control program (ㄷ), and a new community-based Experimental program (E). The new E treatment approach is characterized by active support of persons in an outpatient setting. ${ }^{11}$

Its essential characteristics are as follows:

(1) Hospitalization is virtually eliminated.

(2) Members of the staff work with patients in their nelghborhoods, places of residence and places of employment, providing support and 
Table 1

Resident Patients and Admissions to

State and County Mental Hospitals, United States, Selected Years, 1950-1974

Resident Patients at End of Year

Admisetons

1950

512,501

152,286

1955

558,922

178,003

1960

535,540

234,791

1965

475,202

316,664

1970

337,619

384,511

1974

215,573

374,554

Source: Kramer (1977, p.78). 
teachlng the coping skills necessary to maintain a satisfactory community adjustment.

(3) The staff attempt to minimize the number of patients dropping out of treatment prematurely and to maximize their engagement in jobs and other aspects of responsible, independent community living.

Staff effort was directed not only toward patients but also toward their families and the community setting. Meetings were held with family members to help guide (or in many cases, to stop, at least temporarily) interactions when those were felt to be detrimental to the patient's adjustment. Work with community agencies was also felt to be critical if the $\underline{E}$ program was to succeed. According to Leonard I. Stein, M.D., and Mary Ann Test, Ph.D., developers of the program:

Our major effort was to influence them to respond to patients in a manner that would promote responsible behavior rather than reinforce maladaptive modes of coping with stress. For example, if a patient's behavior was disruptive to other tenants in his apartment building, we would encourage the landlord to talk to the patient directly about his behavior and tell him he would be evicted if it continued. This is contrary to the community's usual response, which is to see to it that the patient's disruptive behavior leads to rehospitalization. That action implicitly gives the patient the message that he is not responsible for his behavior, teaches the patient a maladaptive mode of coping with stress and leads to a hardening of the chronic patient role. 12

Viewed from an economic perspective, the $\underline{E}$ program is a system that confronts patients with the real social costs of their actions, by contrast with the traditional C-type approach, which by and large, does not. Under the $\subseteq$ program, a menta11y-111 person who does not behave in a sociallyacceptable manner--on the job, in his or her roominghouse, in the community-is not punished, but, to the contrary, is typically rewarded by being placed in a protected and subsidized hospital environment which the Individual prefers. Indeed, it is not uncommon for such persons intentfonally to do things, Including violating minor laws so as to be sent 
back to the hospital. Thus, behavior that imposes external costs is actually rewarded!

Under the E program, by contrast, persons who impose costs on others are required to bear the consequences--the landlord's ire, losing a job, time in jail, etc. This is not to say that the patient bears the full social cost; for example, he does not pay for the jail services. It is clear, however, that an essential feature of the. E program is the confrontation of patients by more of the social costs of his or her actions than does the traditional $\underline{C}$-type program. The underlying theory appears to be that behavior of the mentally $i 11$ can be regarded as constrained utility-maximizing; while the person's utility function may be warped, he or she is seen implicitly as responding to relative prices, rewards and punishments.

The experiment itself was conducted in the following manner. Subjects for both the experimental and control programs were all patients seeking admission to Mendota Mental Health Institute (MMHI) who (1) were residents of Dane County, Wisconsin (comprising the City of Madison and the surroundIng area), (2) were between the ages of 18 and 62, and (3) had any diagnosis other than severe organic brain syndrome or primary alcoholism. Beginiting in October of 1972, 130 individuals were randoml; assigned, in equal numbers, and continuing at the rate of 4-6 per month (2-3 in each of the $\underline{E}$ and $\underline{C}$ groups), either to the $\underline{E}$ (community treatment) program or to the $\mathrm{C}$ program (the acute treatment ward in MMHI). The random assignment process resulted in a mix of $\underline{E}$ and $\underline{C}$ groups in which there were no statistically significant differences ( $\$ 05$ level) between persons in the two groups in terms of age, sex distribution, marital status distribution, or time spent in psychiatric institutions (Table 2). 
Table 2

Characteristics of the Two Treatment Groups at Entry Into the Study

Characteristics

Sex

Male

Female

Marital Status

Married

Divorced or separated

Never married

Age (years)

Mean

Standard deviation

Prior time in psychiatric

institutions (months)

Mean

Standard deviation
E Group

$(\mathrm{N}=65)$

36

29

36

29

18

17

17

18

30

30

31.5

30.5

10.5

11.3

16.6

12.5

31.0

28.9 
The $\underline{\mathrm{C}}$ program--the standard program at MMHI-- consisted of progressive short-term In-hospital treatment (generally lasting less than one month) plus traditional after-care provided by community mental health agencies. Patients who were assigned to the $\underline{C}$ group were screened immediately by a member of the hospital's acute treatment unit and were usually, though not always, admitted to the hospital. They remained a median of only 17 days, but in many cases they soon returned to the hospital.

$\underline{E}$ subjects, by contrast, did not enter the hospital at all (except in rare cases when the need for intensive drug therapy or the risk of imminent danger to the Iife of the patient or others dictated some very brief hospitalization). Instead, they received the "community living" treatment approach for 14 months, after which they had no further contact with the experimental unit staff. Although any specific person (In either the $\underline{C}$ or $\underline{E}$ program) was part of the experiment for only 14 months, the experiment spanned a period of nearly three years, since patients entered and left each of the groups at the rate of 2-3 per month.

From the onset of the experiment, great efforts were made to avoid contamination of the study by "Hawthorne" effects. These reflect the tendency of people who are knowingly involved in an experiment to behave differently than they otherwise would simply because of the knowledge tiat they are involved in an experiment. Hawthorne effects might occur because of behavioral changes by patients, treatment staff, or research staff. There is no way to be certain that we were fully successful in avoiding those effects, and, indeed, the nature of the experiment was such that the professional staff and the patients of the E program knew that an experiment was underway.

Several facts lead to the belief, however, that Hawthorne effects are negligible in this case, and that any that are present are likely to bias behavior against, rather than in favor of, the E program: 
(1) patients in the E group knew that they were being treated in an unusual manner, but most were unhappy about being kept out of a hospita1; if their attitudes, behavior and recovery rates were affected at a11 (and it is not clear they were) it would be because of these negative feelings; (2) professional treatment staff working with the $\underline{E}$ group had previously worked on a pilot community-based project; thus, the E-type program was not new to them; (3) interviewers who collected data about both the $\underline{E}$ and $\underline{C}$ groups were not involved in the clinical programs and had no vested interest in the outcome of the experiment; moreover, when interviewers met with research investigators, strict rules permitted talking only about research issues, not about patients; and (4) families and community agencies were of ten aware of the fact that some new treatment approach was being used and evaluated, but it is doubtful that they thought of themselves as being part of an experiment.

\section{Data Collection}

Data were collected for the 65 persons in each group at baseline (admission) and, for most variables, at four-month intervals during the subsequent year. To avoid any distorting effects associated with adjustment of patients who were about to leave the E program, data from only the first twelve months (rather than fourteen) following each patient's admission were included in the analysis. ${ }^{13}$

In order to minimize sample attrition, great pains were taken to find out where former patients had relocated and to interview all of them. Research staff traveled as far as California to interview a patient who had moved there. Family members of a subsample of patients were also interviewed at the time of the patient's admission and again four months later. Information about patient contacts with various 
public and private agencies having been verified with the agencies involved, the economic research team met with staff of these agencies to ascertain the costs of the services provided.

Budget constraints limited the scope of the experiment in two ways: (1) in the duration of the experiment, and (2) in our ability to vary and control different combinations of variables. In any realistic (nonexperimental) application of the community-based program, patients would not likely be restricted to 14 months of participation; thus, our experimental design permits only conjecture regarding whether the Eprogram's success or its costs per patient year would be different if its duration were longer (or, for that matter, shorter).

As noted above, the E treatment approach involves not one but many simultaneous differences from the traditional $\underline{\mathrm{C}}$ approach: (a) patients are not hospitalized; (b) they live and work in the community; (c) people with whom patients are likely to come in contact are asked not to treat them differently from others because they are mental patients; (d) efforts are made by the E-group staff to help patients find and retain jobs; (e) E group staff help patients to budget their money; (f) E group staff accompany patients to social activities; and (g) E-group staff assist patients in a variety of other ways that are not available, ur not available under the same conditions, to $\underline{C}$-group patients.

As a result of the fact that so many treatment variables are being altered simultaneously, any comparison of costs or benefits of the $\underline{E}$ or $\underline{C}$ programs can show only the overall net effect of altering the entire set of variables. As a theoretic ideal (abstracting from the costs of running multiple experiments), it would be desirable to run a set of experiments in which one treatment variable at a time was changed (and 
in various degrees), and additional sets of experiments in which each possible combination of variables was changed (and in various degrees). Only then would we be able to judge the effectiveness of particular inputs in particular combinations and to answer such questions as: how important were the E-program's efforts to augment patients' earnings, as contrasted, say, with the program's efforts to help patients with landlord, cooking, or social difficulties? Would better results (a larger excess of benefits over costs) have accompanied a reallocation of resources between these two types of efforts, or perhaps even the elimination of one or the other of these efforts? Our experiment can only begin to provide data about the total production function for treating the mentally ill.

This conclusion leads to a generalization about all benefit-cost analyses: benefit-cost analyses are almost inevitably incomplete in the sense that they compare only two (or, at most, a few) states of the world--typically with and without some particular project. Since a project is of a particular form, the analysis generally says little or nothing about the benefits and costs of any alternate form, duration, size, location, etc. Thus, just as the mental health experiment does not facilitate assessing an alternative form of the $E$ program, in which, say, job placement efforts were increased or reduced, so the typical benefit-cost analysis of a manpower training program, to take another example, fails to assess the consequences of having a different class size, job placement mechanism or instructional system, Occasionally, more than two alternative states are evaluated (e.g., when the analysis of a possible dam project examines benefits and costs of various sizes 
for the dam). The result, in any case, is examination of only a small portion of the total production function for a particular type of output. Whatever the findings, the possibility remains that some other resource combination would be more efficient than the one(s) evaluated. ${ }^{14}$

\section{ESTIMATING COSTS AND BENEFITS}

Table 3 lists the forms of costs and benefits that would be desirable to measure. In the spirit of the discussion above, the table reflects the need for comprehensiveness of accounts, not ease or difficulty of measurement. With respect to measurement, however--the subject of this section-the following generalizations hold:

Although it is marginal costs and benefits that properly are of concern in any $\mathrm{B}-\mathrm{C}$ analysis, the most readily available data will almost inevitably be averages. Moreover, .

Averages derived from accounting records are frequently biased estimates of true social averages.

Both of these generalizations--and the dangers they imply--hold for the mental health experiment. As regards the "marginal-average" issue, the estimates of benefits and of costs presented here are, in general, averages. Their use may be justified partly by their availability, but within the relevant range of variation, the long run average and marginal costs (or benefits) may be roughly equal.

As regards the use of organizations' accounting data, the estimates that follow are often derived from such records. However, in the case of the cost of treating patients at the MMI (which was by far the largest cost component for the $\underline{\underline{C}}$ group patients), major additions were made to the 
Table 3

Type of Costs and Benefits

\section{Costs}

I. Primary treatment

MMHI.

Inpatient

Outpatient

Experimental center program
Benefits

I. Mental health

II. Physical health

III. Improved labor productivity

IV. Consumer decision-making efficiency

II. Secondary treatment

Social service agencies

Other hospitals (non-MMHI)

Sheltered workshops

Other community agencies

Private medical providers

III. Law enforcement and illegal activity

Police

Courts

Probation and parole

Property damage, human physical injury

IV. Additional maintenance

(Food, housing, etc.)

V. Family burdens

Property and wage losses

Psychic losses

VI. Burdens on other people

(e.g., neighbors, coworkers)

VII. Patient Mortality 
officially recorded accounting cost data to reflect important components of long run soctal costs that had not been reflected in accounting costs (as discussed below). ${ }^{15}$ We turn now to a description of our efforts to measure each of the variables in Table 3 , the results of which, slightly reorganized, are in Table 4 .

\section{Primary Treatment Costs}

The per diem cost of inpatient care at MMHI, as estimated by the State of Wisconsin, differed from the social costs of treatment in three respects, each of which led to an adjustment in the stateprovided cost statistic: (1) the opportunity cost of the land on which the hospital is located had been disregarded; (2) the depreciation of the hospital buildings was based on historical cost rather than replacement cost; and (3) research carried out at MMHI was included in the per diem cost figure for the hospital. The per diem cost estimate by the State, approximately $\$ 70$ in 1973 , was adjusted upward to allow for an opportunity cost of eight percent on the estimated value of the land and the depreciated replacement cost of the physical plant, and it was adjusted slightly downward to account for research activities, which are not appropriately includable as treatment costs. The result was an increase to $\$ 100$ in the MMHI per diem cost, our estimate of long run marginal cost of treatment at that institution.

These adjustments made the MMHI treatment cost data more comparable with the experimental center cost data, for the latter also excluded research expenditures while including commercial rental payments for the center, and these payments presumably reflected a normal return on both the land and the depreciated replacement value of the physical structure. 
C group patients also made use of facilities for outpatient treatment at MMHI. The average cost of such a contact was estimated by MMHI staff to average $\$ 10$ per patient visit.

Calculating a long run average cost for the E program is complicated by the substantial variation in the rate of capacity utilization of its resources over the experimental period. ${ }^{16}$ In order to make the $\underline{E}$ program average cost estimate a closer approximation to what the cost would be for a program that was in continuous, steady state operation, we utilized data on the average cost (per patient per month) for the several months during which time the number of patients in the E program was maximum. ${ }^{17}$ This monthly figure was simply multiplied by 12 to obtain an estimate of annual cost per patient.

\section{Secondary Treatment Costs}

"Secondary treatment" includes a wide range of medical and related helping services provided by various agencies, institutions and professions, and available to both groups of patients outside of their respective primary treatment facilities. The category thus includes hospitals and psychiatric institutions other than MMHI, halfway houses, sheltered workshops, visiting nurse, counseling and educational services, etc.

Patient interviews provided initial data on the number of service units received or contacts with secondary providers; these were verified by all major local providers, but not--for reasons of cost--by small local providers (e.g., doctors) or out-of-town providers, with the exception of other state-run hospitals in Wisconsin.

Measures of the costs of treatment by the numerous secondary providers were short of the ideal of long run average social cost--and not simply (or 
even primarily) because of input price distortions. Even in those few instances in which we had access to cost data--and most providers were unwilling to provide it--time and staff constraints dictated that we simply accept the providers' own estimates of the costs of servicing the $\underline{C}$ and $\underline{E}$ group subjects. Another generalization about benefitcost analyses can be made: in any benefit-cost analysis in which cost information is derived from records of firms or other institutions, budgetary constraints together with organizations' reluctance to provide access to their financial records generally lead to the use of the imperfect and biased cost data.

\section{Law Enforcement Costs}

Another form of social costs that may vary with the treatment mode involves law enforcement. We were able to obtain data from patient interviews on the number of police and court contacts, the number of nights spent in jail, and the number of contacts with probation and parole officers. Reported contacts with the Madisen Police Department and the Dane County Sheriff's Office were verified, but those with other departments were not. The costs per contact or per overnight were obtained by methods essentially the same as those used for secondary treatment costs. 18

\section{External Costs Caused by Patients' Illnesses}

Patients interact with other persons in a wide range of settings. While we do not have information on all such interactions, we have examined two categories of individuals for whom these external (to the patient) costs 
are likely to be particularly great: members of the patients' immediate families; and other people who have suffered because of illegal or at least disruptive behavior on the part of patients. We obtained data on the burdens imposed on people in these two categories, both from interviews with patient families at baseline (time of admission to the $\underline{E}$ or $\underline{C}$ programs) and after four months, as well as from records of courts and law enforcement agencies.

These measures are, however, clearly imperfect, and difficult valuation problems exist. Many of the burdens can be translated into costs only by essentially arbitrary methods. What, for instance, is the cost of worry or of the disruption of a person's normal routine? In principle, the willingness of the affected persons to avoid these costs is measurable, but we were unable to develop such monetary values. Our limited ability to deal with external costs suggests another generalization: even when relevant forms of costs are not quantified in monetary terms, they can at least be enumerated explicitly.

In the interviews with family members (at baseline and after four months), families were asked whether or not they had experienced work or school absences, disruption of domestic or social routines, trouble with neighbors, or stress-related physical ailments as a result of the patient's illness. ${ }^{19}$ They were also asked if the patient's illness had forced them to purchase services formerly provided by the patient; if they had paid for psychiatric treatment or medication received by the patient; whether they had given cash or large non-cash gifts to the patient; the interviewer then rated each family as suffering a "severe," "moderate," "mild," or "no" burden from the patient's illness and what, if anything, about the patient worried them. 


\section{Patient Maintenance Costs}

On the one hand, it is arguable that "maintenance" is required simply to live and thus is not a function of mental health status and so should be excluded from the table. On the other hand, the E program involved, as a deliberate aspect of its treatment methodology, encouraging independent living arrangements; therefore, the resulting higher level of maintenance costs is a real cost of this treatment mode. ${ }^{20}$ Thus, in principle, we should include as real costs only the incrememtal maintenance costs attributable to the E program. In practice, however, not only is it extraordinarily difficult to identify these additional costs, it is not even clear that this increment is positive. For example, if the $\underline{E}$ program were more effective, it might well result in more efficient consumption behavior and hence lower consumption/maintenance costs (expenditures) than would otherwise have been incurred. ${ }^{21}$

\section{Improved mental health of the patient}

Improving the mental health of patients is ostensibly the primary goal of any current treatment program. Such improvements may well increase the productivity and stability of patients as consumers and may bring external benefits in the forms discussed above, but to many people these results are secondary to the benefits of patients' feeling better, i.e., more satisfied with Iife. ${ }^{22}$

These effects are difficult' to value in monetary terms, even conceptually. For ordinary goods and services, a patient's behavior might reveal his or her willingness to pay. As regards the mentally ill, however, It is not clear either what normative meaning should be attached to the 
person's stated willingness to pay for better health or what kinds of inferences about that willingness should be made from any observed behavior.

In the quantitative work presented below there are no pecuniary values for the state of a subject's mental health per se or for changes in that state. This is one of the variables for which quantitative but non-pecuniary indicators seem most appropriate. Three such indicators are tised: (1) varfous objective measures of quality of life, such as the number of leisure-time social groups the subject reported having attended in the month preceding the interview (at 4, 8, and 12 months); (2) a trained interviewer's judgment of the presence or absence of various symptoms of mental illness, plus an overall "global illness" assessment; and (3) the subject's own assessment of how satisfied he or she is with life in general (1iving situation, friends, food, work, etc.). Each of these is described in the next section, where the empirical results are presented.

\section{Improved Productive Behavior of Patients}

One potential benefit of any treatment program for mentally ill adults is an improvement in a patient's lifetime ability to function as an economic producer. A full accounting for increased productivity would encompass not only increases in marginal productivity in the organized market but also increases in non-market productivity, such as unpaid work around the home and increased investment in human capital (perhaps via education) which can be expected to increase the present value of future productivity. 
Conceptually, we want to measure any increase in productive potential attributable to treatment. A re-allocation of patients' time between work and non-work is not necessarily an efficient consequence of treatment. Thus, to anticipate a finding reported below, if the $E$ patients worked more than did the $\underline{C}$ patients, the resulting differential in earnings would not necessarily constitute a benefit.

There are two reasons for believing, however, that an increase in mentally ill persons' earnings resulting from treatment should be regarded as a social benefit even if such an increase was a result of increased hours of work (and decreased hours of "leisure"). First, the menta11y ill person's opportunity cost of work time at the margin--that is, the reservation wage--might be close to zero. This is not implausible, given the difficulty that the mentally ill have in gaining employment for the desired number of hours per week. Indeed, given their emotional problems, the negative psychological feelings associated with leisure--not being with other people in a work setting, not doing work that receives social approval-might well be such that the marginal value of leisure is even negative. 23 Second, persons with mental illness typically have difficulty in retaining a job. Thus, if one treatment mode results in a greater increase in earnings, this might reasonably be interpreted as a differential program benefit whether the added earnings occurred because of an increased hourly rate of pay or because an increase in the amount of time worked.

Wages paid in competitive employment are a reasonable proxy for the marginal product of the individual's labor, even though the absence of perfectly competitive markets means that market wages do not generally equal the value of the worker's marginal product. Wage determination in sheltered workshops, however, is not a directly market-determined process. 
Workers (patients) do produce goods and services in workshop programs and are paid "wages." 24 Their productivity, however, is often far below that of persons competitively employed to produce a similar product and, indeed, the patients' pay is often far below the minimum wage. State and federal laws require that wages in sheltered workshops be determined by comparison with the wage rates and productivity prevailing in the competitive market. If a worker's productivity is, say, 60 percent of that of competitively employed individuals doing the same type of work, he or she must be paid 60 percent of the going wage for that job. It appears that the sheltered workshops in the Madison, Wisconsin area do make a serious effort to pay the mandated wage, which is an approximation to the value of the marginal product of the work.

Data on work experience and earnings were obtained from the quarterly interviews with patients. As a rough check on the accuracy of responses, Social Security wage records were examined (in the 92 percent of cases for which records could be obtained). Information on sheltered workshop employment and earnings was provided by the workshops themselves.

Housework or child care work for one's own family typically involves no pecuniary exchange, which makes the evaluation of such work difficult. We did try but in the end were unable to obtain a useful measure of the quantity or value of household work.

Participation in an educational or training program is an investment activity to the extent that it increases productive potential and hence the present value of future earning capacity. Given the brief duration of our experiment (one year) it would be hazardous to project the value of any education or training that a subject might have obtained during the 
single year when, for at least part of the year, the person was acutely i11. No data were obtained for the effect of each treatment mode on this human-capital investment variable.

\section{Increased Work Stability}

Wages, either actual or imputed, are not the only useful measure in terms of which the effects on productivity of the two treatment modes should be assessed. Work stability is another. Current stability provides some evidence of future stability, and hence can serve as an indicator of expected earnings beyond the period of the experiment. Thus, we attempted to measure the differences in the job stability of the $\underline{C}$ and $\underline{E}$ group patients.

One such measure of productive stability is "absenteeism"--the percentage of days on which the patient was expected to be at a job but was absent. A second measure of stability is the number of "beneficial" and "detrimental" job changes made by the patient. Any statistically significant differences in the number of beneficial changes (e.g., moving to a job with a higher wage rate) and detrimental changes (e.g., being fired) can reasonably be considered evidence of differences in the effectiveness of the two treatment programs.

Improved Consumer Decision-making

One potential benefit of a successful treatment program is an improvement in the subject's ability to manage his or her finances. Indicators of such benefits, let alone monetary values for them, are difficult to devise. We present below information on two indicators, both of which are, at most, only suggestive. One is the subject's expenditures on insurance, 
reflecting the patient's attention to the future and its uncertainties. The psychiatrist and psychologist directing the experiment believe that, within limits, increased attention to the future is a sign of improved mental health. It should be noted, however, that while expenditures on insurance may be an indicator of improved health and, hence, of social benefits, such expenditures do not themselves constitute a measure of benefits that is additive to benefits in the form of, say, added earnings.

The same is true for a second indicator of more efficient consumer behavior for the mentally ill--saving behavior. Again the psychiatrists' interpretation is that more saving, within limits, reflects increased, and healthy, concern for the future. As an operational matter, we were able to obtain useful data only on whether the subject did or did not have a savings account; neither the size of the account nor the presence of savings in other forms could be ascertained.

These two indicators are far from satisfactory. They are included primarlly as filustrations of a class of benefit variables that is conceptually relevant but easily overlooked--more efficient use of available resources. By including them explicitly, the $\mathrm{B}-\mathrm{C}$ analyst underscores to the policy-maker the necessity to make a judgment about their imporțance:

The conceptually relevant period for analysis is the period over which all of the benefits are realized and all the costs incurred, perhaps a lifetime or even longer if mentally ill parents affect the mental or physical health of their children. It is likely that for any treatment program the time pattern of costs and of benefits are not the same, costs being concentrated at the onset of the treatment program and benefits being spread out over a longer interval. Moreover, the time patterns may well 
differ among alternative treatment modes. As a result, a one-year analysis--even if it were complete--may provide a misleading picture of lifetime benefit-cost relationships, both for any given treatment mode and across treatment modes.

This is to say that a treatment program should be viewed and evaluated as an investment yielding returns (pecuniary and nonpecuniary) through time. Thus, the ideal $B-C$ analysis would identify the time patterns of net benefits as well as a discount rate. ${ }^{25}$

Figure 1 sketches a plausible time pattern for the differentials between programs in total benefits and in total costs. It portrays costs that, during the course of the first four months of treatment, are increasingly greater for the average E program patient. The extra cost of the E program, $C_{E}-C_{C}$, then diminishes, while the excess of benefits of the $\underline{E}$ program over the $\underline{C}$ program increases, so that by the end of month 12, the higher cost of the E program is offset by its extra benefits.

\section{FINDINGS}

In this section we present estimates of the variables for which measures were described in Section 3. As the reader will expect by now, some measures are not in dollar form. All benefits and costs shown in Table 3 are listed again in Table 4, with either dollar quantities, nonmonetary numerical estimates, or simply question marks. I am particularly proud of the question marks. They highlight variables which, while relevant to comprehensive $B-C$ analysis, have not been quantified. They are often omitted from B-C analyses, but here their inclusion, if only with question marks, serves to underscore the fact that quantitative 


\section{Figure 1}

Hypothetical Net Benefit and Cost Streams, Two Treatment Modes

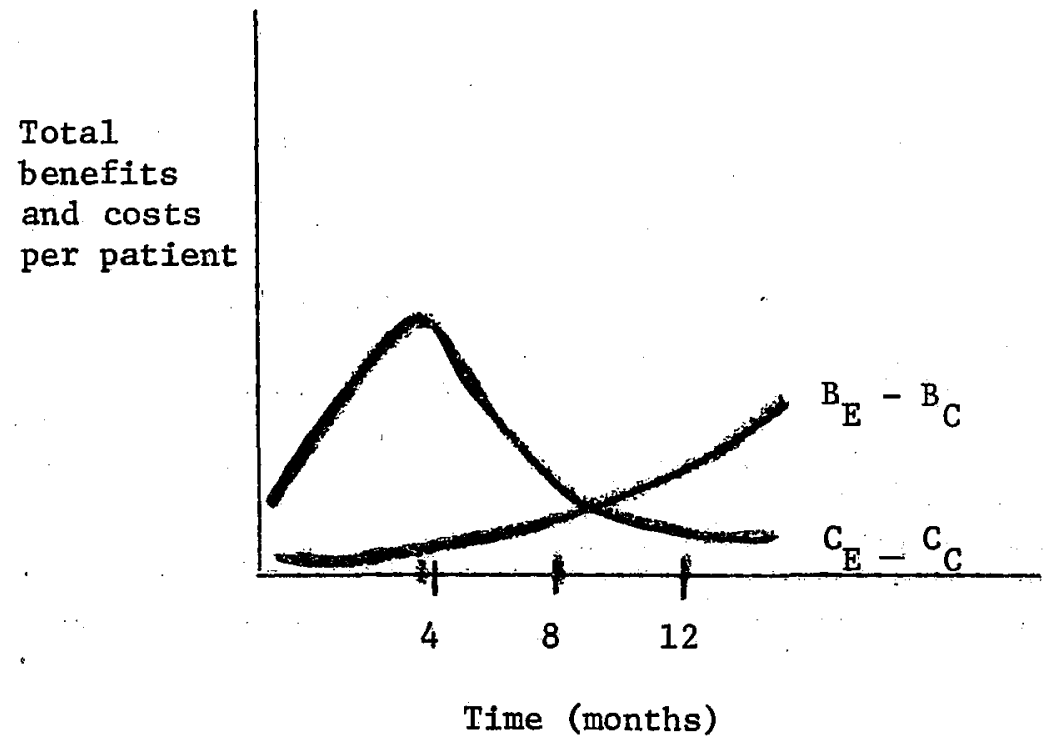


Table 4

Costs and Benefits Per Patient, Experimental and Control Groups, for 12 Months Following Admission to Experiment

COSTS Costs for which monetary estimates
have been made

1. Direct treatment costs

Mendota Mental Health Institute (MMHI) Inpatient Outpatient

Experimental center program

Total

\begin{tabular}{|c|c|}
\hline $\begin{array}{l}\text { Control } \\
\text { Group (C) } \\
\text { (1) }\end{array}$ & $\begin{array}{c}\text { Experimental } \\
\text { Group (E) } \\
\text { (2) }\end{array}$ \\
\hline
\end{tabular}

$\$ 3096$

Sheltered workshops

Madison Opportunity Center, Inc., and Goodwill

Industries

Other community agencies Dane County Mental Health Center

Dane County Social Services

State Dept. of Vocational Rehabilitation

Visiting Nurse Service

State Employment Service

Private medical providers

Tota1

3. Law enforcement costs

Overnights in jail

$\$ 159$

Court contacts

Probation and parole

Police contacts

Total:
189

44

$\overline{\$ 409}$
42

0

$\overline{\$ 3138}$

$\$ 1744$

91

870

$\$ 646 \$-1098 * *$

\begin{tabular}{rr}
$\$ 4$ & $\$-3002 * *$ \\
0 & $-42 * *$ \\
4704 & $4704 @$ \\
& \\
\hline 4798 & $\$ 1660 @$
\end{tabular}

$\$ 646$ - $\$-1098 *$

$779 * *$

55

41

185

0
4

22.

$\overline{\$ 2142}$

50

25

$-5$

$-16 *$

209

$24^{\mathrm{b}}$

$23 * *$

$-1 *$

3

$-10^{\mathrm{a}}$

12

$\overline{\$ 1838}$

$\overline{\$-304} \mathrm{e}$

\section{.}

.


Contro1
Group (c)

(1)

4. Maintenance costs

5. Family burden costs

Lost earnings due to the patient

Total costs for which monetary estimates have been made
$\$ 1487$

$\$ 120$

$\overline{\$ 7296}$
Experimental

Group (E)

(2)

$\underline{E}-\underline{C}$

$\$ 1035$

$\$-452$

\section{Other costs}

6. Other family burden costs

Number of families reporting physical illness due to the patient

Pèrcentage of family members

7. Burdens on other people (e.g. Neighbors, Coworkers)

8. Illegal activity costs

Total

Total No. of arrests for felony
1.0

0.2

0.8

$-0.2^{a}$

0.2

$0.0^{\mathrm{a}}$

9. Patient mortality costs (percentage dying during the year)

Suicide

Natural causes
1.5

0
1.5

3
0

3 


\section{BENEFITS}

Control
Group (C)
$(1)$$\quad \begin{aligned} & \text { Group (E) } \\ & \text { (2) }\end{aligned}$

Benefits for which monetary estimates have been made

1. Earnings ${ }^{h}$

From competitive employment

From sheltered workshops

Total

Other benefits

2. Labor market behavior

Days of competitive employment per year

Days of sheltered employment per year

Percentage of days missed from job

No. beneficial job changes

No. detrimental job changes
$\$ 1136$

$\$ 1136$

32

$\overline{\$ 1168}$
$\$ 2169$

$\$ 2169$

195

$\overline{\$ 2364}$
$\$ 1033 * *^{d}$

$\$ 1033 * * d$

$163 * *^{d}$

\$11960 


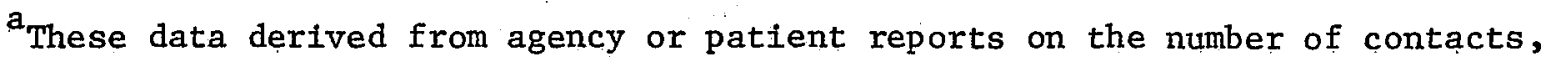
patient reports being used only when it was not possible, or was excessively costly, to obtain the relevant information from the agency. Estimates of the per contact were obtained from the agency.

${ }^{b}$ Data from the Department of Vocational Rehabilitation (DVR) were available only for the 28-month study period as a whole, which included the followup period after the experiment. The per patient costs presented in Table 1 are $12 / 28$, or 43 percent of the 28-month data, reflecting average cost for one year. The figures reflect some double counting because much of the DVR expenditures go for payments to other agencies that are included in cost section 2 of the table. We have been able to account for, and to exclude, DVR payments to the sheltered workshops but not, for example, to hospitals. The $\$ 24$ difference is biased upward by the omission of counseling expenses * attributable only to $\underline{\mathrm{C}}$ group members.

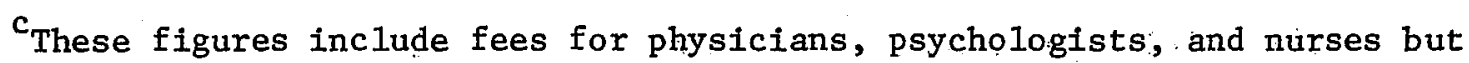
exclude any assocịațed laboratory fees.

${ }^{d_{T h e s e}}$ data are derived from patient reports and as such subject to misreporting. Patient reports were used only when it was not possible (or was excessively costly) to obtain the relevant information from an independent source. In some cases, when an interviewer suspected faulty reporting, individual spot-checks were made with the agency in question; agencies that were not able to provide us with information on all patients were sometimes able to provide it on this spot-check basis.

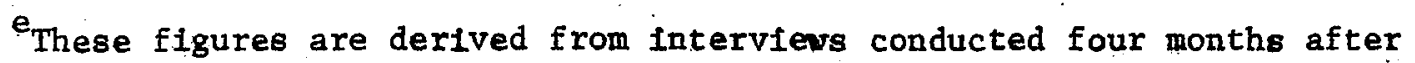
admission with 22 families of $\underline{E}$ group patients and 18 families of $\underline{C}$ group patients (34\%: of the E group, $27 \%$ of the $\underline{C}$ group). The other families 
were not interviewed because: (1) they lived outside of Dane County (23\% of each group); (2) the subject or the family refused to cooperate ( $12 \%$ of the E group, $22 \%$ of the $\mathrm{C}$ group); or (3) the relative could not be contacted ( $31 \%$ of the E group, $28 \%$ of the $\mathrm{C}$ group). The questionnaire examined the families' experience in the two weeks preceding the interview only, and, with some trepidation, these figures are inflated to an annual average. The reduced sample size and the single interview yielded data which must be interpreted with caution.

$f_{\text {These figures were derived by multiplying the number of days family }}$ members missed work because of the patient by a daily wage of $\$ 24$ (or $\$ 3$ an hour).

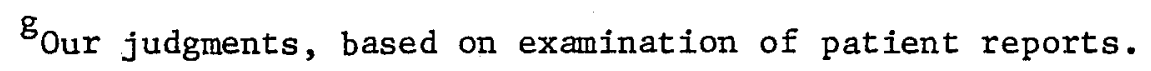

harnings do not include value of fringe benefits, if there were any. 'Interviewers' assessments. 
estimates--monetary or other--have not been made. They are thus an explicit reminder of the need for policy makers to judge their importance.

Tables 5 and 6 are companions to Table 4. Table 5 shows the real quantity units which lie behind the pecuniary data in Table 4; when multiplied by the respective prices, these quantities yielded the dollar amounts shown in Table 4. The blank items in Table 5 reflect the fact that for some forms of monetized costs and benefits separate price and quantity data were not available to the research team. Table 6 gives some detail about the mental health measures listed in Table 4. It bears repeating that this $B-C$ analysis deals with only two alternatives, the status quo (C program) and the particular constellation of community-based efforts (E program). The question is whether the $\underline{E}$ program is "better"--on either cost or benefit grounds or "both-- than the $\underline{C}$ program, not whether the $\underline{E}$ program (or the $\underline{C}$ program) is better than any of a large number of other alternative programs.

\section{Costs}

Several findings are apparent from Table 4. (1) Average total dollar costs are of substantial magnitude- $\$ 7,300-\$ 8,100$ per patient year--whichever treatment approach is used, and only about half of the total is in the form of primary treatment costs. (2) Average total dollar costs of mental illness including its treatment are some 10 percent higher for the $\underline{E}$ program than for the $\underline{C}$ program. (3) As anticipated, the forms of costs are quite different for the two treatment appraaches. For example, the E program entails 50 percent greater direct treatment costs--\$4,798 per E program fatient compared with $\$ 3,138$ per $\underline{C}$ program 
Table 5

Quantities of Services or Resources Utilized Per Patient, Experimental and Control Groups, for 12 Months Following Admission to Experiment

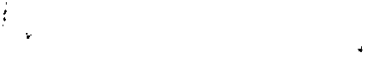

CosTs
Group

$\underline{E}$

1. Direct treatment costs

Mendota Mental Health Institute (MMHI)

Inpatient days

Outpatient visits

31.4

6.1

3.0

0.0

2. Indirect treatment costs

Social service agencies

Other hospitals (not MMHI)

$\$$

$\$$

Sheltered workshops days

5.6

52.3

Other community agencies

Dane County Mental Health Services Board (contacts)

Dane County Social Services (contacts)

State Employment Service (days)

3.8

6.8

2.8

$61 \div 8$

0.5

0.2

Private medical providers: contacts

1.9

1.3

3. Law enforcement costs

Overnights in jail

15.9

15.7

Court contacts

0.3

0.2

Probation and parole (occurrences)

2.2

1.5

Police contacts (arrests)

0.5

0.7 
Symptomatolog $\mathrm{y}^{\mathrm{a}}$

At end of:

4 months

8 months

12 months

Social relationships ${ }^{\text {b }}$

4 months

8 months

12 months

\section{Patient satisfaction with $11 \mathrm{fe}^{\mathrm{c}}$}

4 months

8 months

12 months
E group was significantly (.05 level or better) less symptomatic on 4 of the 13 measures (including global illness); on the other 9 , no significant differences.

E group was significantly (.05 or better) less symptomatic on 4 of the 13 measures (including global illness); on the other 9 , no significant differences.

$\underline{E}$ group was significantly $(.05$ or better) less symptomatic on 7 of the 13 measures (Including global illness); on the other 6 , no sigrificant differences.

E group had significantly (.05) more (2.1 vs, 0.7$)$.

E group had significantly $(.05)$ more (1.7 vs. 0.8):

E group had significantiy (.05) more (1.9 vs. 0.6).

No significant difference between $\underline{\mathbf{E}}$ and $\underline{\mathrm{C}}$.

No significant difference between $\underline{E}$ and $\underline{\mathbf{C}}$.

E group significantly $(0.5)$ higher mean score.

a. Thirteen items were considered, consisting of the following 12 symptoms plus an overall independent assessment of "global illness": depressèd mood, suicidal trends, anxiety or fear, expression of anger, social withdrawal, motor agitation, motor retardation, paranoid behavior, hallucinations, thought disorder, hyperactivity-elation, and physical complaints.

b. Number of social groups attended in the last month.

c. On a 5-polnt scale from 1, "not at' all satisfied"-with friends, living situation, leisure activities--to 5, "very much satisfied". 
patient. Similarly, while there is only about a 15 percent difference (in favor of the E group) in total indirect treatment costs, some components of indirect costs show a much greater difference. For example, the "other hospital" component of E program costs is some 60 percent smaller than that of the $\underline{C}$ program, about $\$ 650$ per patient for the E group. Sheltered workshop costs are 9 times as large annually for the $\underline{E}$ group- $-\$ 870$ versus $\$ 91$. Maintenance costs are 40 percent greater for the $\underline{\mathrm{C}}$ group program patient--\$1487 versus $\$ 1035$ per patient year.

Recall the hypothesis that the E patients would have more contacts with the law because they spent more time in the community. Table 4 shows that the opposite was the case, whether the measure is number of arrests, number of felony arrests, or the associated law enforcement costs. E group patients, by our measures, also imposed fewer burdens on their families, although the differences are not statistically significant. Finally, it should be noted that there is not a statistically significant difference in the number of deaths from natural causes, and no difference at all in the number of suicides. Table 4 intentionally stops short of placing a monetary value on lost human lives. Estimates of such values have been made elsewhere, but both the conceptual foundations of the various approaches and the resulting estimates vary a great deal. ${ }^{26}$ As a result it seemed best to refrain from introducing explicit valuations of life into the table.

\section{Benefits}

Treatment of the mentally ill can be viewed as having the goals of helping the patients to "feel better" and to be more "productive" members 
of society. Operational measures of achievement of these goals are required for a benefit-cost analysis. Tables 4 and 6 show four types of benefit measures.

(1) Earnings and labor market behavior. The discussion in Section 3 pointed out that while in most contexts earnings from working more are an overestimate of net welfare benefits, for the mentally ill this may not be so. The marginal disutility of work for the mentally ill, who are frequently unable to obtain or to retain a job, may well be close to zero. It may even be negative; that is, the satisfaction from working in a socially-approved way may well exceed the pecuniary rewards.

Table 4 shows that $\underline{E}$ group patients showed substantially better labor market performance as measured by earnings. They averaged more than twice the earnings of control group members, and almost all of the excess was from competitive employment rather than from sheltered workshops. The greater earnings were realized despite the $\underline{E}$ group's higher (but not significantly different) absenteeism rate--7 percent compared with 3 percent for the $\underline{\mathrm{C}}$ group--and, in general, workers were not paid for days missed.

(2) Consumer decision-making: Do the treatment programs differ in their ability to aid patients to use their resources more efficiently, that is, to maximize their utility subject to the budget constraint? The conventional assumption that consumers are successful as utility maximizers can reasonably be questioned for the mentally ill. We can view their behavior as either the failure to maximize utility or their maximization of an "inappropriate" utility function (one they would not have but for their illness); in either case, however, treatment can help patients to be more effective decisionmakers. 
Data problems were particularly serious in this area. We were able to estimate insurance expenditures and the presence or absence of a savings account, both of which reflect forward-thinking behavior, as discussed in the preceding section. However, there were not significant differences between the programs, and in any case, these measures leave much to be desired. The differences that were found, however, favor the E program.

(3) Mental health status as judged by outside observers. There is no single measure or indicator of mental health. One approach adopted In this experiment involved a trained observer meeting with patients and reporting on the presence or absence of various adverse sympotoms. The top panel of Table 6 reports the findings that the $\underline{E}$ group averaged fewer symptoms at the 4 and 8 month interviews and still fewer at the 12 month interview. These findings are even more striking when it is realized that the E group was actually more symptomatic at the time of admission (a fact not reported in the table).

Panel 2 in Table 6 presents another indicator of mental health status, frequency of social relationships. Since the mentally ill tend to withdraw from social contacts, more frequent contacts are interpreted as favorable. $\underline{E}$ group members consistently had more social relationships than did $\underline{C}$ group patients. (The difference did not grow, however, through the year of treatment.)

(4) Mental health status as judged by patients. Panel 3 of Table 6 reports that although there was no signiffcant difference between $\underline{E}$ and $\underline{C}$ patients' reported "satisfaction with life" after 4 and 8 months, the $\underline{E}$ group was significantly more satisfied by the end of month 12 . 
Al1 of these findings indicate that $\underline{E}$ patients, who were spending a significantly greater proportion of their time in the community, were becoming better adjusted socially and were experiencing improvement in their quality of 1ife--measured in various ways and from differing perspectives--relative to controls.

Several general comments about these quantitative findings are in order.

(1) Our initial concern about the danger of mistaking a shift in the form of cost for a change in the level of cost proved to be well founded. If we had neglected, for example, to examine the costs of providing sheltered workshop services, we would have found that average total costs were virtually identical for the two programs, whereas, because the workshops were used far more by the E patients, the $\underline{E}$ program was 10 percent more costly in total. And if we had limited our attention to hospitals in the county, rather than extending it to other "out of town" hospitals, we would have underestimated the $\underline{\mathrm{C}}$ program per patient cost by $\$ 808$ per year while underestimating the E program cost by only $\$ 264$ per year.

(2) The enhanced earnings of the E group patients apparently led to a reduction in the amount of maintenance costs borne by others. The \$1,196 of increased patient earnings per year under the E program was accompanied by a decrease of $\$ 452$ in maintenance costs. Assuming equivalent living stadnards for the two groups, the added earnings of the $\underline{E}$ group were, in effect, "taxed" at a 38 percent marginal rate.

(3) The somewhat greater costs of the $\underline{E}$ program appeared to bring an even greater increase in benefits. Tables 4 and 6 show that the E program, while more costly in real terms, has added benefits in the form of labor market earnings alone that exceed the added costs. When the mental health 
benefits, as described in Table 6 , are considered, the net advantage to the E program grows further.

Summing up the quantitative findings we find that the experimental programs: (a) cost an additional $\$ 800$ per patient year, but in return it produced increased productivity (as measured by earnings) of some $\$ 1,200$; (b) showed evidence of enhancing the planning and decision-making skills of patients (insurance and savings behavior); (c) decreased patient mental illness symptomatology; and (d) increased patient satisfaction with life. The evidence suggests that the community-based $\underline{E}$ approach would justify the added cost, assuming that the B-C relationship estimated in a single-year experiment would hold over time. ${ }^{27}$

6. THE DISTRIBUTION OF COST BURDENS

Benefit-cost analyses typically are regarded as efforts to determine the allocative efficiency of proposed governmental projects or programs. ${ }^{28}$ As such, questions of who bears the costs and who reaps the benefits are generally not examined, reflecting economists' unwillingness to make interpersonal comparisons of utility. As a matter of positive economics, however, our ability to predict governmental behavior surely would be enhanced if we understood better the distributional consequences of governmental programs. ${ }^{29}$

There are many ways to view distributional effects. The data in Table 4 can serve as a starting point from which to identify who receives the benefits and who bears the costs. Patients receive the earnings, less some percentage that is taxed, and patients also receive any increased satisfaction with life. Family members benefit from any reduced burdens. Taxpayers gain (or lose) from decreases (increases) in utilization of public1y-provided services. 
A priori, I expected to find that the division of monetary costs (the only costs dealt with in Table 7) of the $\underline{E}$ and $\underline{\mathrm{C}}$ programs would differ substantially among federal, state and local taxpayers, and private persons, and this has indeed been the case. The traditional treatment approach (C program) for the mentally ill has placed heavy emphasis on hospitalization-and mental hospitals have been financed largely by state governments. At the time our experiment was begun, the governor of Wisconsin was pressing the legislature to close one of the two state mental hospitals in order to reduee the state budget. While this would surely be a cost-reducing action in the first instance, it was not clear that state fiscal burdens would be reduced in the aggregate. The mentally ill might impose increased cost burdens on other institutions receiving some state finance (e.g., prisons and sheltered workshops). It was even less clear how any savings to the state would compare with added costs imposed on other levels of governments and on nongovernmental persons and institutions.

Table 7 was developed to shed light on the distributional effects of choosing one treatment approach rather than another. It shows the initial incidence of monetary costs for both programs. (The possibility of shifting is not examined here.) The dollar costs shown in Table 4 have been allocated according to the funding sources for each cost item; since many of the individual costs in the earlier table were funded by several different sources, numbers appearing in Table 7 have a complex relationship with those in Table 4.

Columns 1 and 2 show how our cost estimate of $\$ 7,296$ per patient-year for the $\underline{C}$ program is distributed among the four classes of governmental and private groups. It is noteworthy that although state mental hospitals are frequently thought of as the basic locus of treatment (and hence of costs), 
Table 7

Incidence of First Year Costs-Control and Experimental Programs

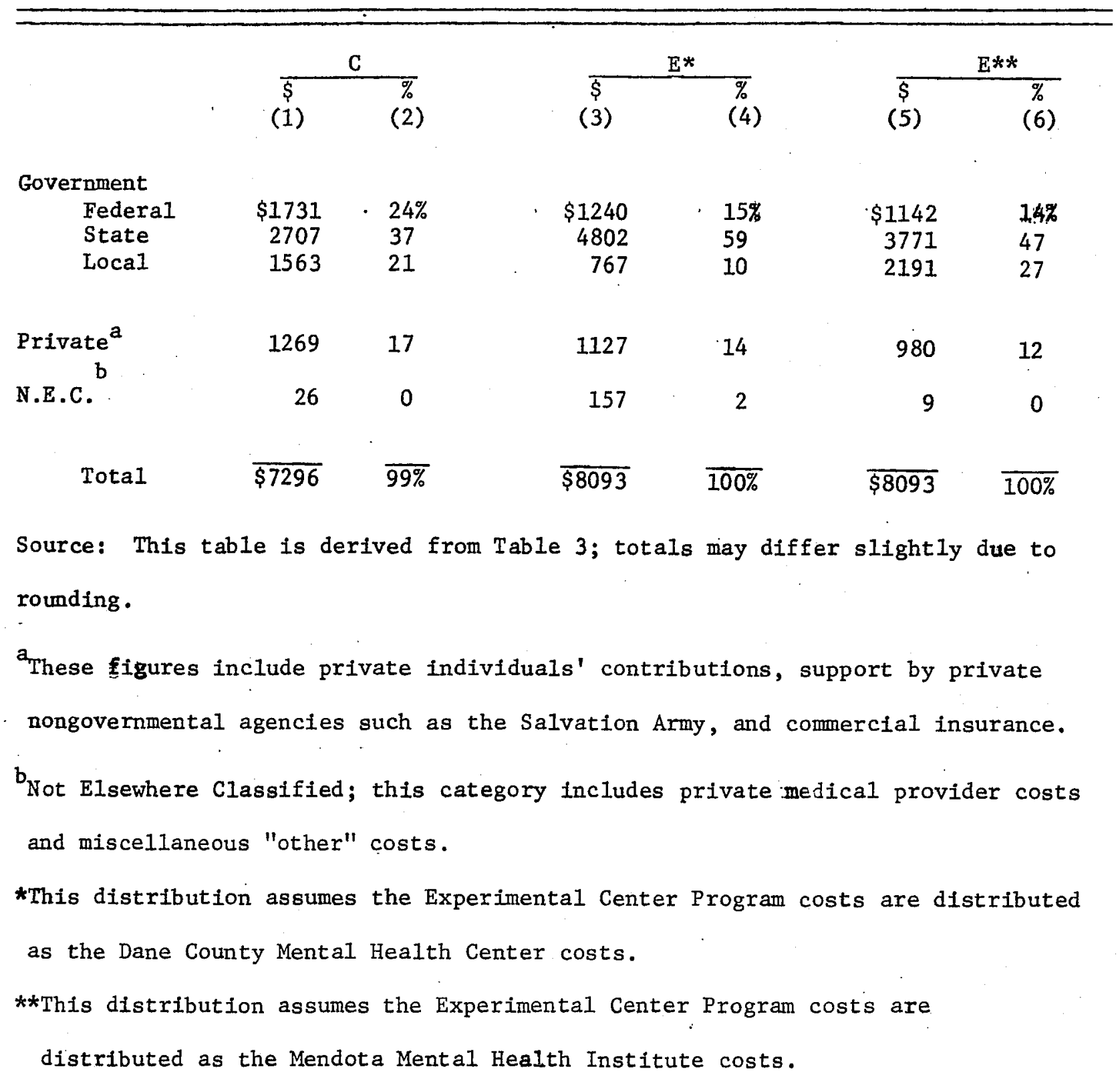


only 37 percent of total monetized costs are borne by the state under the

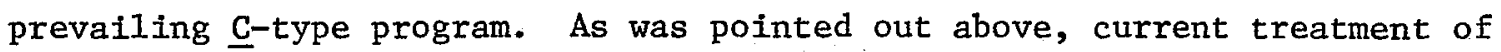
the mentally ill does not generally involve long-term custodial care, and so the average patient in the $\underline{\underline{C}}$ program is out of a hospital the vast majority of the time even in the year following an acute episode. When the person is outside the hospital, he or she is likely to be utilizing a wide variety of mental health and related services that are financed either by private donors or by local and federal governments.

Columns 3-6 of Table 7 reflect two alternative assumptions as to the distribution of costs if the experimental approach were adopted. Columns 3 and 4 show the distribution under the assumption that the E program was run by the Dane County Mental Health Center and was financed from various sources in the same proportion as the Center is now financed; columns 5 and 6 assume the program would be run by MMI and financed as that institution is now financed. 30

Pressure by various governors and state legislators to close state mental hospitals appears to reflect a somewhat mistaken view regarding the importance of state funds in financing the care and treatment of the mentally i11. As columns 3-6 in Table 7 show, by contrast with columns $1-2$, the shifting of treatment from the currently predominant $\underline{C}$-type program to the community-based E-type program would increase, not decrease, both the percentage and the absolute dollar-cost burden on state taxpayers under either of the two assumptions regarding how the Experimental Center Costs would be shared. (There is no basis for saying what would have happened to either costs or benefits if the state mental hospital had been closed, or if the patients in the E program had been kept out of the hospital but had not 
been provided with the resources for the E program; neither of these counterfactuals was part of the experimental design.)

Table 7 also shows that the experimental program, while being about 10 percent more costly than the control program, has the effect--under either the columns 3-4 or the columns 5-6 assumptions regarding Experimental Center Cost distributions--of reducing dollar cost burdens on private donors and on federal taxpayers. Tax burdens on state taxpayers, by contrast, are sharply higher under the community-based E program, whichever finance method is used. Burdens on local taxpayers either rise or fall, depending on which of our two assumptions is made as to who would finance the Experimental Center Costs. Table 7 deals with the costs for which monetary values appear in Table 4; the distribution of nonmonetary costs, however, is also relevant to a full assessment of the welfare effects of the two treatment approaches.

\section{DISAGGREGATING PATIENTS BY DIAGNOSIS}

The overall average comparison of $\underline{E}$ and $\underline{C}$ groups, as in Table 4, can mask systematic variation in costs and benefits for particular "types" of patients. Patients are, after all, inputs to the mental health production process. Thus, the relative costs and the relative benefits of the $\underline{E}$ and $\underline{C}$ production processes may vary among patients whose mental illnesses differ. If this were the case, it would hold that the B-C relationship for treating some types of mental illness would favor the $\underline{E}$ program and for other types it would favor the $\underline{\mathrm{C}}$ program technology.

Table 8 shows the benefits and costs in the manner portrayed in Table 4, but for each of the three diagnostic categories (determined at time of admission) for which the sample size was meaningful: schizophrenics, other 
Table 8

Costs, and Beneftts Per Patient, Experimental and Control Groups

for the 12 Months Following Admission to Experiment

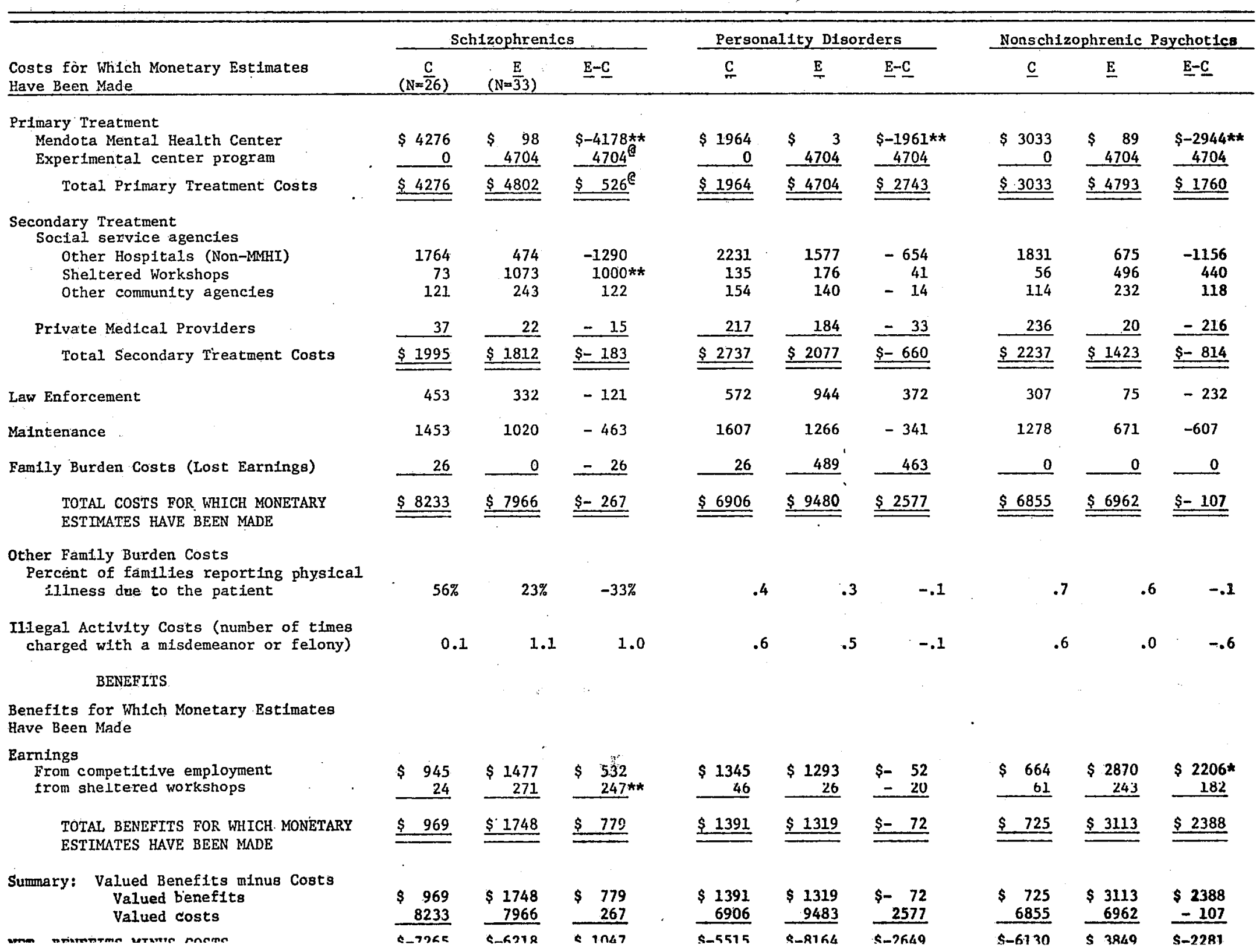


peychotica (nonschisophrente), and persons with personality disorders

(PD). The direct treatment cost of the $\underline{E}$ patients could not be est Imated separately by diagnostic category; therefore the tables show the sabe cost figure.

The contrasts in both benefits. and costs for persons with each type of mental illness is striking. Direct treatment costs for the $\underline{\mathrm{C}}$ parients averaged \$1964 per PD patient, but were more than twice as large, \$4276, per schizophrenic patient. Law enforcement costs for E patients ranged from $\$ 75$ per year for nonschizophrenic psychotic patients, $\$ 332$ for schizophrenics, to \$944 for PD patients. Moreover, while the law enforcement cost for nonschizophrenic psychotics was four times as large under the $\underline{C}$ program as under the $E$ ( $\$ 307$ compared with $\$ 75)$, the relative costs were reversed for the PD group. The $\underline{\mathrm{C}}$ program patients were associated with considerably smaller costs--\$572 compared with $\$ 944$. (The differences are not statistically significant at the .05 level, but this is not surprising, given the sample sizes.) When the "total costs for which monetary estimates have been made". are examined across diagnostic classes, we again find notable differences. The costs of. the two treatment technologies as applied to nonschizophrenic psychotics differ by only a little over $\$ 100$. For schizophrenics, average costs of $\underline{E}$ and $\underline{C}$ programs differ by less than $\$ 300$, with the $\underline{C}$ costs being greater. For PD patients, however, the difference was nearly $\$ 2500$ per patient year. Variation on the benefit side is just as noteworthy. Table 4 had shown that $\underline{E}$ patients earned twice the approximately $\$ 1100$ earned by $\underline{C}$ patients. Now we see that earnings within the $\underline{C}$ group ranged from $\$ 725$ for nonschizophrenic psychotic patients to nearly $\$ 1400$ for those with personality disorders. And $\underline{E}$ group earnings ranged from $\$ 1319$ for $P D$ patients to $\$ 3113$ for nonsch1zophrenic psychotics. The differential earnings between the $\underline{E}$ and $\underline{C}$ treatment approaches was some $\$ 2400$ 


\section{for ponsehizophrentc paychotic patients, in favor of the $\underline{E}$ progran, Dut 1t was only $\$ 70$ for PD patients and in favor of the $C$ group.}

The disaggregated findings in Table 8 are important not simply because they disclose variation around the means in Table 4, but because the diagnostic categories are discernible at baseline. Thus, patients could be sorted out at the time an acute problem develops, with treatment--E or $\underline{\text { C--depending }}$ on diagnosis. The data, imperfect as they are, suggest that the E program is "preferred"--in terms of monetized benefits and costs only--for schizophrenics and other psychotics but not for PD patients.

\section{ANOTHER LOOK AT PROGRAM EFFECTIVENESS}

The fact that $\underline{E}$ and $\underline{C}$ group patients were randomly assigned does not preclude the possibility that systematic differences in relevant variables will affect the experimental results. In this section a regression approach is used as another way to examine the overall effectiveness of the $\underline{E}$ and $\underline{C}$ treatment technologies. First we reexamine the effect of treatment mode on patient earnings and then on "clinical ratings". (See Table 6 and accompanying discussion.)

\section{Effects of Treatment Technique on Earnings}

In Table 9, equation 1 presents the findings from a regression (OLS) of patient earnings (in dollars per year), T.E., both on four background variables-- age, years of schooling, dummies for marital status ( 1 if married) and $\operatorname{sex}$ ( 1 if female)--as well as on a dummy variable, ELC, for the treatment group ( 1 if E). Recall that Table 4 had shown that E patients averaged more than $\$ 1100$ higher earnings than $\underline{C}$ patients during the 12 -month period; but 
Table 9

Effects of Treatment Mode on Earnings

$$
\text { (1) } \begin{aligned}
\mathrm{T} . \mathrm{E} . & =-804+13 \mathrm{Age}+182 . \mathrm{Yr} \mathrm{Ed}+585 \mathrm{Marr}-1322 \mathrm{Fe}+768 \mathrm{E} / \mathrm{C} \\
\mathrm{t} & =(.66)(.61)(2.27) \quad(1.29) \quad(3.26) \quad(1.93) \\
\mathrm{R}^{2} & =.19 \\
\mathrm{~N} & =101^{2}
\end{aligned}
$$

(2) Add Earnings in Prior Year, Y Lag

$$
\begin{aligned}
\text { T.E. }= & -1719-2 \text { Age }+176 \text { Yr Ed }-87 \text { Marr }+115 \mathrm{Fe}+66 \text { Y Lag } \\
& (1.85) \quad(.13) \quad(2.90) \quad(.25) \quad(.33) \\
\mathrm{R}^{2}= & .54
\end{aligned}
$$

(3) Add Dummy for Schizophrenic, and for Personality Disorder Diagnoses

$$
\begin{aligned}
\text { T.E. }=-1399- & 5 \mathrm{Age}+157 \mathrm{Yr} \mathrm{Ed}-164 \mathrm{Marr}+63 \mathrm{Fe}+64 \mathrm{Lag} \\
& (0.31)(2.55) \quad(0.43) \underset{(0.18)}{(8.25)} \\
+ & 8 \mathrm{~S}+217 \mathrm{PD}+1237 \mathrm{E} / \mathrm{C}-807 \mathrm{~S}^{*} \mathrm{E}-1647 \mathrm{PD}^{* \mathrm{E}} \\
& (0.02) \quad(0.39) \quad(2.32) \quad(1.14) \quad(2.00)
\end{aligned}
$$

where S and PD refer to schizophrenic and personality disorder diagnoses, and $S * \mathrm{E}$ and $\mathrm{PD} * \mathrm{E}$ refer to interactions of each diagnosis with participation in the E treatment program.

$$
\mathrm{R}^{2}=.57
$$

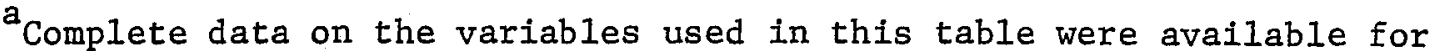
only 101 of the total of 130 patients. We are aware of no reason to expect selection bias. 
equation 1 , Table 9 estimates the difference attributable to the $E$ program at $\$ 768$. Apparently, the random assignment process produced some systematic differences across groups.

Even more striking is the effect, in equation 2, of controlling for patients' earnings in the year prior to participation in the experiment (in either the $\underline{E}$ or $\underline{C}$ program). When this variable, YLag is added, the apparent effect of the E program falls further (from \$768 to \$507), its statistical significance declines, and the value of $\mathrm{R}^{2}$ rises to .54 , from .19 in equation 1 . The YLag variable was added to control for the possibility--which seems to be the actuality-that patients in the $E$ program happened by chance to have been more productive prior to admission; in that case they might well have had greâter post-admission earnings even if the $\underline{E}$ program were less effective than the $\underline{\mathrm{C}}$ program:

A comparison of equations 1 and 2 also shows that adding YLag changed drastically the coefficient on the sex variable; Fe, from a negative and high1y significant $\$ 1322$ to a positive but not significant $\$ 115$. The importance and significance of marital status also dropped sharply, and the sign changed.

Next, in equation 3, I added dummy variables for type of patient's illness, following the reasoning of the preceding section. (Dummies were added for only the two diagnoses with the largest sample sizes--schizophrenics and personality disorders. Between them they accounted for about two-thirds of the patients in both the $\underline{E}$ and $\underline{C}$ groups.) The contrast with the results in Table 8 are marked. Table 8 showed that schizophrenic patients in the E program received $\$ 780$ more earnings than did their $\underline{\mathrm{C}}$ group counterparts. 
Equation 3 of Table 9 implies, however, that, ceteris paribus, a schizophrenic patient who is in the E program can expect only $\$ 430$ more than a $\underline{\mathrm{C}}$ group schizophrenic patient, (\$1237 less \$806). For a patient with a diagnosis of $\mathrm{PD}$, the results are even more striking. The $\underline{E}$ program appears to be less productive than the $\underline{C}$ program, at least in terms of earnings; participation in the E program is associated with lower earnings than could be expected by a PD patient treated in the more traditional $\underline{C}$ mode-- $\$ 1237$ less $\$ 1647$, or $\$-410$. Table 8 also had shown lower earnings for the $E$ patients, but only $\$ 72$.

The regression analysis advanced the preceding analysis by controlling explicitly for previous earnings. There was, however, a potentially serious problem of interpretation: the data on prior earnings were obtained directly from patients in the baseline interviews, and the accuracy with which patients recalled and reported their earnings for the previous 12 months is questionable. As a result, it is not clear whether more confidence or less should be placed in the regression results than in the tabulations in Tables 4 and 8 .

\section{Effects of Treatment Techniques on Clinical Rating}

Table 6 reported on differences between $\underline{E}$ and $\underline{C}$ patients in terms of interviewers' judgments on clinical symptomatology. Now we examine the relative effectiveness of $\underline{E}$ and $\underline{C}$ approaches within a regression framework, controlling explicitly for the patients' clinical rating at baseline and looking particularly at interactions of diagnostic type with the treatment technology.

In Table 10, equation 1 simply regresses a patient's score (on a scale from 0 , best, to 7 , worst) at the end of 12 months of treatment, on that patient's score at baseline, SLag, and on a dummy variable for participation 
Table 10

Effects of Treatment Mode on Clinical Rating

(1) $S=2.25+.25 \mathrm{~S} \mathrm{Lag}-.65 \mathrm{E} / \mathrm{C}$

$t=(4.25) \quad(2.02) \quad(1.59)$

$\mathrm{R}^{2}=.05$

$\hat{N}=94^{a}$

(2). Add diagnoses and interaction variables

$S=1.65+.16 \mathrm{~S} \mathrm{Lag}-.23 \mathrm{E} / \mathrm{C} \cdot 2.05 \mathrm{~S}+.57 \mathrm{PD}-1.03 \mathrm{~S} * \mathrm{E}=.17 \mathrm{PD} \mathrm{E}^{*}$ $\begin{array}{llllllll}(2.46) & (1.25) & (.36) & (3.23) & (.86) & (1.15) & (.17)\end{array}$

$R^{2}=.18$

${ }^{a}$ Complete data on the variables used in this table were available for only 94 of the total of 130 patients. We are aware of no reason to expect selection bias. 
in the $E$ program ( $I$ if $E$ ). There are no surprises, but the prior judgment that the baseline score should be controlled seems to be supported; one additional point on the baseline score was associated with an additional 0.25 of a point after 12 months, suggesting that patients who were more symptomatic at the beginning of the experiment were likely to remain so but with improvement (at a statistically significant level).

The negative sign on $\underline{E} / \underline{C}$ is consistent with the Table 6 results; participation in the $\underline{E}$ program is associated with an improvement of nearly two-thirds of a point in the clinical score, although the significance level is not high by conventional standards.

Only 5 percent of the variance in $S$ can be explained by the two variables. in equation 1 . This rises to 18 percent, however, when diagnostic categories are cortrolled for; in equation 2 of Table 10, dummy variables have been added for nonschizophrenic psychotic and personality disorder diagnoses, and interaction terms added for each of those diagnostic groups and participation in the E group program. Using the clinical rating score as the dependent variable, by contrast with earnings (Table 9), participation in the $E$ program is associated with somewhat more favorable effects (fewer symptoms) for the PD group ( 0.17 points on the 7.00 point scale) and considerably more favorable effects for the schizophrenic group ( 1.03 points), although reither is statistically significant. The beneficial effect of receiving E progran treatment is thus larger for these two diagnostic groups than for others. A comparison of equations 1 and 2 in Table 10, hctever, shows that the $\underline{E}$ group schizophrenic patients benefited nearly twice as much, in clinical rating terms $(.23+1.03=1.26$-see equation 2$)$, as the average of all E group patients (.6.5 in equation 1): on the other hand, E group 
patients with personality disorders gained only $.23+.17=.40$ points on the clinical rating.

\section{CONCLUDING REMARKS}

This paper has three objectives.

The specific goal is (1) to report the methodology and findings of a benefit-cost analysis of a controlled experiment in the treatment of the mentally i1l. In the debate over national health insurance, scant attention has been given to mental illness and even less to the choice among alternative types of delivery systems. The research reported here supports the hypothesis that hospitalization of the mentally ill is, except for emergency situations, less effective than communitybased treatment of approximately equal cost.

These empirical findings should be interpreted, however, with'caution. The experiment was conducted in one geographic area (Dane County, Wisconsin) during one time interval (October 1972 to March 1976) with each subject participating for only a 14-month period. The economic, social, and political environment during that time and in that area could have influenced the experimental findings in important but poorly understood ways. The same experiment operated in a different environment (e.g., one with a higher or lower unemployment rate or a larger or smaller city) might have produced substantially different outcomes.

(2) A more broad goal of this paper is to show how any benefit-cost analysis--not simply one in the mental health area--can provide seriously misleading, if not incorrect, results if the range of costs and benefits are not viewed comprehensively and if forms of costs and benefits that are 
not easily measured in monetary terms are omitted. Empirically, we haye found confirmation of the hypothesis that the forms taken by the social costs of alternative programs can be so different that it is easy to mistake a change in the form of costs for a change in their leve1.

(3) A third goal is to underscore the importance and feasibility, for any benefit-cost analysis, of encompassing all variables deemed relevant, whether or not monetary valuation of them is carried out. Presentation of outcomes in quantitative but nonmonetary terms can be useful, as the analysis presented here has shown. Moreover, the explicit presentation of even those relevant variables for which no quantitative measures at all can be developed is a desirable part of what the economist can do to inform public policy decisions. In the end, however, benefit-cost analysis is not a substitute for judgment, but only an aid in using judgment. 
FOOTNOTES

${ }^{1}$ A helpful textbook is Mishan (1976). Examples of benefit-cost analyses are Beesley and Foster (1965), Garms (1971), and Weisbrod (1971). For a recent collection of such evaluations, see Haveman and Margolis (1977). A useful, though somewhat dated survey is Prest and Turvey (1965). For a theoretic discussion, see Boadway (1974).

${ }^{2}$ On "social experiments," see Rivlin (1971) and Haveman and Watts (1977).

${ }^{3}$ See, for example: "Ever since the dawn of civilization, consciously or unconsciously man has always speculated about costs and benefits. Today we use technical jargon and we can turn to impressive statistical information, yet even for contemporary affairs it is almost impossible to rejach objective conclusions about costs and benefits when it is a question of health and environment. The fact of the matter is that it is impossible to quantify certain intangibles and a number of value judgments are by necessity subjective and arbitrary," Cipolla (1976). For other critical appraisals, see Maass (1966) and Titmus. (1970).

${ }^{4}$ Much of the theoretic welfare economics 1iterature on compensation conceives of socially costless, lump-sum, nondistorting, taxes and transfers. More recent work examines the effects of compensation insettings where distortions are likely. For example, see Cordes and Weisbrod (1979).

5 For example, a program to reduce accidents in a subway by reducing the speed of trains might appear to be highly beneficial until it is recognized that the above-ground accident rate rose as subway riders 
shifted to private autos. Total accident costs could even have increased as the form of cost shifted from subway accidents to road accidents.

${ }^{6}$ other perspectives, such as that of a governmental budget administrator who might be interested simply in cash flows would produce a different benefit-cost analysis.

${ }^{7}$ Indeed, these external effects and utility function interdependencies presumably go far to explain the major role played by the government sector in the treatment of the mentally ill.

${ }^{8} \mathrm{~B}-\mathrm{C}$ analysis in many program areas (nursing homes and securities regulation are two others) must go beyond a narrow criterion of direct beneficiaries' willingness to pay, either because the direct beneficiaries are badly informed and unable to evaluate their benefits and costs, or because external effects are sizable. In either event, benefits to the persons directly involved--as they perceive them--will be erroneous measures of social benefits.

${ }^{9} \mathrm{~A}$ recent book that surveys the literature on valuation of human life is Jones-Lee (1976), especially chapter 2.

10 With virtually all the mental patient's needs provided within the hospital, the longer the period of hospitalization, the more difficult it is for the patient, once discharged, to cope with the ordinary problems of daily living in the outside world. Outside the hospital the individual usually has sharply fewer sources of guidance and support than he or she has as an inpatient. As a result, any new life crises is likely to find the patient seeking the shelter of renewed hospital confinement. 
${ }^{11}$ Two researchers at the Mendota State Hospital--now Mendota Mental Health Institute (MMHI)--Dr. Leonard I. Stein and Dr. Mary Ann Test, developed the treatment program which they felt would avoid this cycle of discharge and rehospitalization. Subsequently, they designed a controlled experiment to test the new treatment model. Dr. Stein was then Director of Research at MMHI and is now Professor of Psychiatry, University of Wisconsin-Madison. Dr. Test, a psychologist, was then Associate Director of Research at MMHI. She is now Assistant Professor of Social Work, University of Wisconsin-Madison.

${ }^{12}$ Stein and Test (1977). This paper also contains more detail on the experimental design and experimental treatment approach.

13 Data were also collected during a subsequent 14-month follow up phase, but this paper deals only with the initial period, for it was only during this interval that different treatment modes were in effect.

${ }^{14}$ In a subsequent mental health treatment experiment, some alternative programs were tried (e.g., one that reduced the utilization of sheitered workshops), but they were not subjected to an intensive analysis.

15 Providers of services (hospitals, community organizations, etc.) were the major source of data on costs. In some instances, providers gave us figures on average total costs per patient-day of per some other unit of patient contact. They often also gave us information on utilization of their services by patients in the $\underline{E}$ and $\underline{C}$ groups, but when they could not or would not provide such information, we fell back on other sources, in particular, interviews with patients. In either case, we simply multiplied the average cost figures by the corresponding utilization data to derive 
the total costs incurred on behalf of the patients in each group. In other. instances, service providers gave us data on the total costs incurred in treating or assisting not a statistically average person but the particular patients whose names we provided (without denoting whether the patients were from the $\underline{E}$ or $\underline{C}$ group). Property taxes were deducted from the $\underline{E}$ program property rental expenditures so as to make these costs more comparable to the tax-free state-owned property occupied by MMHI. We might have chosen, instead, to impute a cost to the MMHI and to estimate the marginal cost of the unpriced public services consumed by both the $\underline{E}$ and $\underline{C}$ programs rather than to utilize property tax payments, actual or imputed. But the additional difficulty of these alternatives and their necessarily conjectural nature suggested the alternative we utilized. Be deducting property tax payments for the $\underline{E}$ program center and by making no addition to the MMHI cost figure to account for the marginal costs of public services, we have understated the real costs of both the $\underline{E}$ and $\underline{C}$ programs, although this omission would not bias our finding if the levels of utilization of unpriced public services is similar for the two programs.

${ }^{16}$ The E program, unlike the hospital-based $\underline{C}$ program, started with a patient population of zero; the patient population grew at the rate of 2-3 persons per month, reaching a peak of some thirty patients and subsequently declining to zero. (Each patient was in the program for 14-months, but the entire experiment lasted some three years.) During nearly half of the study the E program had a great deal of slack capacity in the form of under-utilized staff time, building and equipment. This. overcapacity 
(resulting from staff indivisibility) led to higher average costs than would have been the case in a steady state. (It also led, however, to more staff time per patient, and thus, perhaps, to higher quality care.)

${ }^{17}$ In the judgment of the E program clinical staff, "full capacity" utilization was never reached; thus, our procedure mav still overstate long run equilibrium cost for the E program. By the same token, however; the hospital facility at MMHI, used for the $\underline{C}$ program, was also operating below capacity-although it operated at essentially a constant level over the study period, by contrast with the variable capacity utilization of the $\underline{E}$ program.

${ }^{18}$ To be sure, it is not likely that all law enforcement costs for each group are attributable to--and hence are costs of--mental illness, but it seems reasonable to attribute differences between the groups to. differences in treatment outcomes.

${ }^{19}$ Information obtained from the family burden interview is limited in two major respects. The size of the sample is sma11--49 out of 130-and the follow-up period--four months--is short relative to that of the whole study. (Budgetary constraints and concern about the burden imposed by the interviews themselves limited the number of follow-up interviews.)

20 Because participation in the $\underline{E}$ treatment program was limited to 14 months, following which treatment reverted to the conventional $\underline{C}$ type treatment, family members presumably did not adjust the size of their residence to the (temporary) absence of the patient. If the E program were made permanent, however, such adjustments would occur, and with them would come reduced housing cost burdens on family members. Thus, in the 
long run any higher level of maintenance costs for the $\underline{E}$ program would be at least partially offset by lower family burden costs.

${ }^{2} I_{\text {To }}$ further complicate the matter, some of the real maintenance costs incurred by $\underline{E}$ group members were probably financed by those patients themselves out of the higher level of their earnings (a variable discussed below in connection with the analysis of benefits). It is social costs, not expenditures per se, that we seek to measure. Direct measurement of the social costs of maintenance was not feasible, however, and so we proxied them by expenditures but were unable to obtain reliable data on patient expenditures, if any, out of their own income.

22 The latter may be interpreted as a reflection of independent utility functions, with the health state of the (mentally) ill entering the utility functions of the non-ill, or it may be interpreted as a Rawlsian-type concern by the non-ill about the possibility that they too may someday become ill and in need of outside assistance. Either way, improved mental health per se is a benefit both to patients and others.

23 With respect to patients' reservation wage, it may be useful to consider possible changes over time. (1) Early in the experiment, the E group patients were, to some extent, pressured into working; as a result of this work being involuntary, any increase in the patients' earnings overstates the increase in their real income, given the nature of their utility functions at the time. While the increased earnings (productivity) would constitute a gross benefit from the particular treatment program, the disutility of work would constitute a gross cost. (2) Later in the experiment, however, when patients' utility functions changed in response to therapy, their attitudes toward work appeared to change; working became 
more voluntary. During this period the disutility of work became less then the earnings, and, indeed, the disutility might even be negative--as would be the case if the patients got great satisfaction from being able to do socially approved work. The shorter the duration of the early period, the more reasonable the treatment of earnings as a measure of net benefits, for it is during the later period that the assumption of low, or zero, reservation wage is more plausible. (This point grew out of a stimulating conversation with Car1 Dahlman.)

${ }^{24}$ Workshop clients also require farily intensive supervision; the cost of this supervision is included in secondary treatment costs.

${ }^{25}$ On the choice of a discount rate, see Baumol (1968) and U.S. Congress (1968).

26 Jones-Lee $(1976)$

${ }^{27}$ Controlled social experiments in other program areas have raised similar questions about the effects of the limited duration of the experiment and especially about whether behavioral effects (e.g., on labor supply) would differ if a program were permanent. See, for example, Metcalf (1973).

${ }^{28}$ See, for example, Harberger (1971).

${ }^{29}$ Cordes and Weisbrod, for example, have shown (see note 4 ) that a government agency that is required to conpensate persons harmed as an unintended consequence of its activities may well alter its project selections as a direct result of the distributional (i.e., the compensatory) constraint. Thus, distributional equity and allocative efficiency are entwined. 
${ }^{30}$ In the actual experiment virtually all expenditures of the $E$ program were financed by a federal grant. If the program were introduced, however, in a non-experimental setting, the state and local govermental roles in financing it would doubtless be sizable. 


\section{REFERENCES}

W. Baumo1, "On the Social Rate of Discount," American Economic Review, Sept. $1968, \underline{58}, 788-802$.

M. Beesley, and C. Foster, "The Victoria Subway Line: Social Benefit and Finances," Journal of the Royal Statistical Society, 1965, 67-88.

R.W. Boadway, "The Welfare Foundations of Cost-Benefit Analysis," Economic Journal, $1974,926-939$.

J. Cordes, and B.A. Weisbrod, "Governmental Behavior in Response to Compensation Requirements," Journal of Public Economics, 1979, 11, 47-58.

W. Garms, "A Benefit-Cost Analysis of the Upward Bound Program," Journal of Human Resources, Spring 1971, 4, 206-220.

A.C. Harberger, "Three Basic Postulates for Applied Welfare Economics," Journal of Economic Literature, Sept. 1971, 9, 785-7.97.

R.H. Haveman and J: Margolis, Public.Policy and Expenditure Analysis, Chicago. 1977.

-----, and H.W. Watts, "Social Experimentation as Policy Research: A Review of Negative Income Tax Experiments," in V. Halverstadt and A. Culyer, eds., Public Economics and Human Resources, Paris 1977, 239-255. Also in Glenn V. Glass, ed., Evaluation Studies Review Annual, New York. 1976. M.W. Jones-Lee, The Value of Life: An Economic Analysis, Chicago. 1976. M. Kramer, Psychiatric Services and the Changing Institutional Scene, 1950-1985. National Institute of Mental Health, Analytical and Special Study Reports Series B, No. 12, 1977.

A. Maass "Benefit-Cost Analysis: Its Relevance to Public Investment Decisions," Quarterly Journal of Economics, May 1966, 80, 208-15. 
C.E. Metcalf, "Making Inferences from Controlled Income Maintenance Experiments," American Economic Review, June 1973, 62, 478-483. E.J. Mishan, Cost-Benefit Analysis, New York. 1976.

A.R. Prest, and R. Turvey, "Cost-Benefit Analys1s, A Survey," Economic Journal, $1965,685-705$.

A. Rivlin, Systematic Thinking for Social Action, Washington DC. 1971.

L.I. Stein, M.D., and M.A. Test, Ph.D., "An Alternative to Mental Hospital Treatment: I. Conceptual Model, Treatment Program and Clinical Evaluation," University of Wisconsin-Madison mimeo, 1977, 9-10.

R.M. Titmus, The Gift Relationship: From Human Blood to Social Policy, London. 1970.

U.S. Congress, Joint Economic Committee, Economic Analyses of Public Investment Decisions: Interest Rate Policy and Discounting Analysis, Washington DC. 1968.

B. Weisbrod, "Costs and Benefits of Medical Research: A Case Study of Poliomyelitis," The Journal of Political Economy, 1971, 79, 527-544. 